\title{
INTERFERÊNCIA DO ACIDO ASCÓRBICO NA DETERMINAÇÃO DE AÇÚCARES REDUTORES PELO MÉTODO DE LANE E EYNON
}

\author{
José Torquato de Queiroz Tavares*, Ricardo Luis Cardoso, João Albany Costa, Francisco de Souza Fadigas e Antônio \\ Augusto Fonseca \\ Centro de Ciências Exatas e Tecnológicas/Centro de Ciências Agrárias, Ambientais e Biológicas, Universidade Federal do Recôncavo \\ da Bahia, 44380-000 Cruz das Almas - BA, Brasil
}

Recebido em 23/4/09; aceito em 25/11/09; publicado na web em 23/3/10

\begin{abstract}
ASCORBIC ACID INTERFERENCE IN THE DETERMINATION OF REDUCING AND TOTAL SUGARS BY LANE AND EYNON METHOD. Two studies, both set up as completely randomized design, in a 5x5 and 7x5 factorial schemes, evaluated the interference of 5 and 7 ascorbic acid concentrations and 5 glucose or 5 sucrose concentrations, respectively, on the determination of total and reducing sugars by Lane and Eynon method. The ascorbic acid reducing power (AARP) over the Fehling liquor interfered in the results of total and reducing sugars. On average the AARP was equivalent to 74.83 and $69.71 \%$ of the reducing power of glucose and of hydrolyzed sucrose, respectively. The ascorbic acid was stable in all study conditions.
\end{abstract}

Keywords: reducing power; vitamin C; Fehling solution.

\section{INTRODUÇÃO}

Vários métodos de análise foram desenvolvidos para medir a concentração total e os tipos de carboidratos presentes nos alimentos, sendo que os mais precisos e poderosos são os métodos cromatográficos: a cromatografia em camada delgada (CCD), a cromatografia gasosa (CG) e a cromatografia líquida de alta resolução (CLAE). Os carboidratos podem ser também separados por eletroforese. ${ }^{1}$

Esses métodos analíticos apesar de mais precisos por serem de custo elevado não estão disponíveis para a maioria dos laboratórios das indústrias de alimentos, assim como para a maioria dos laboratórios de pesquisa que utilizam os métodos químicos, muitos deles métodos oficiais.

Os métodos químicos usados para determinar carboidratos na forma de monossacarídeos e oligossacarídeos são baseados no fato de que muitos desses apresentam poder redutor (em meio alcalino a quente) sobre o cobre, a prata, o ferro e/ou outras substâncias, produzindo complexos coloridos, ou precipitados que podem ser quantificados.

A concentração dos carboidratos pode ser determinada por titulação (Lane-Eynon, EDTA e Luff Schoorl), por gravimetria (Musson-Walker, Tolens) ou por espectrofotometria (Somogyi-Nelson, ADNS, Antrona, Fenol-Sulfúrico). ${ }^{2}$ As sensibilidades são diferentes, as leituras colorimétricas são muito precisas e as titulométricas, relativamente grosseiras - neste caso, o sucesso da análise repousa na prática do analista. ${ }^{3}$

Os carboidratos não redutores podem ser determinados pelos mesmos métodos de determinação dos açúcares redutores, desde que eles primeiro sejam hidrolisados, enzimática ou quimicamente, para se tornarem redutores.

Os métodos químicos clássicos conhecidos (método de Lane e Eynon, de Benedict, complexométrico de EDTA, de Luff-Schoorl, de Musson-Walker, de Somogyi-Nelson) são fundamentados na redução de íons cobre em soluções alcalinas..$^{1,2}$

O método de Lane-Eynon baseia-se no fato de que os sais cúpricos, em solução tartárica alcalina (solução de Fehling), podem ser reduzidos a quente por aldoses ou cetoses transformando-se em sais cuprosos vermelhos, que se precipitam, perdendo sua cor azul primitiva, conforme Figura 1. O tartarato, ao unir-se ao cobre, formando um complexo solúvel, impede a formação de hidróxido cúprico

*e-mail: torquato@ufrb.edu.br insolúvel que teria lugar se existisse cobre livre na solução alcalina. Como critério de positividade da reação verifica-se a formação de óxido cuproso vermelho tijolo, que precipita. ${ }^{4}$

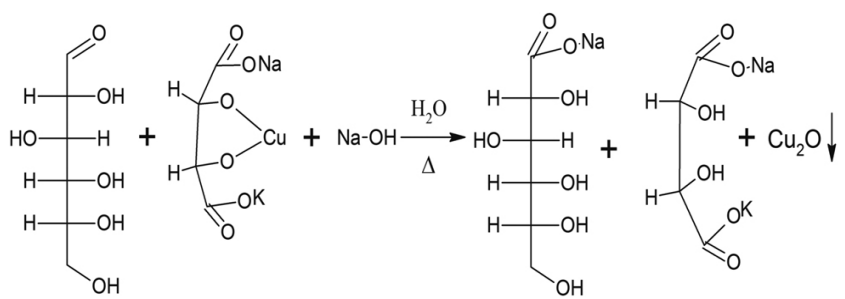

Figura 1. O tartarato de sódio e potássio forma um sal como $\mathrm{Cu}^{+2}$ (azul anil) que sofre posterior redução a tartarato e óxido cuproso $\left(\mathrm{Cu}_{2} \mathrm{O}\right.$ de coloração vermelho tijolo) que precipita e o açúcar redutor é oxidado formando um sal sódico como produto

Existem dois fatores importantes a serem seguidos neste método para maior exatidão dos resultados. A solução deve ficar constantemente em ebulição durante a titulação, porque o $\mathrm{Cu}_{2} \mathrm{O}$ formado pode ser novamente oxidado pelo $\mathrm{O}_{2}$ do ar, mudando a cor novamente para azul; A titulação deve levar no máximo $3 \mathrm{~min}$, porque pode haver decomposição dos açúcares com o aquecimento prolongado. A relação entre o cobre reduzido e o açúcar redutor não é estequiométrica, o resultado é obtido de tabelas ou padronizando-se a mistura de Fehling com uma solução de açúcar com concentração conhecida, e é geralmente expresso em glicose. ${ }^{5}$

Todos os monossacarídeos são redutores por possuírem grupos carbonílico e cetônico livres e o mecanismo de óxido-redução está relacionado com a formação de um enediol, função fortemente redutora em meio alcalino, que interconverte aldoses e cetoses. A glicose, em meio alcalino, é rapidamente transformada no enediol, levando à formação de frutose e de manose, e este composto, conhecido como redutona, ao ser oxidado à função aldônica causa a redução dos íons cúpricos. ${ }^{3}$

As desvantagens dos métodos químicos baseados na redução de metais e outros compostos são: os resultados dependem de um tempo de reação preciso, a temperatura da reação e concentração dos reagentes devem ser cuidadosamente controladas; não distingue os diferentes tipos de açúcares redutores; é susceptível à interferência 
de outros tipos de moléculas que atuam como agentes redutores. ${ }^{1}$

A vitamina $\mathrm{C}$ ou ácido L-ascórbico é um carboidrato derivado do ácido L-gulônico que pode ser sintetizado química e biologicamente a partir da D-glicose ou D-galactose; quando puro é uma substância branca, cristalina. A característica mais importante do ácido L-ascórbico é a sua oxidação a ácido L-deidroascórbico para formar um sistema redox, que pode ser oxidado irreversivelmente ao ácido 2,3-dicetogulônico com perda da atividade redutora. Esse ácido pode ser convertido em ácido oxálico e ácidos L-treônicos e, posteriormente, em pigmentos escuros. ${ }^{6,7}$

$\mathrm{O}$ ácido L-ascórbico, quando na forma ionizada, é um ácido diprótico relativo às hidroxilas nos carbonos 2 e 3 , solúvel em água $\left(0,33 \mathrm{~g} \mathrm{~mL}^{-1}\right)$ e insolúvel na maior parte dos solventes orgânicos, ponto de fusão $=190-192{ }^{\circ} \mathrm{C}$, potencial redox $-\mathrm{E}_{\mathrm{o}}=0,166 \mathrm{~V} \mathrm{em} \mathrm{pH}$ 4,0, absorção máxima $=245 \mathrm{~nm}$ ( $\mathrm{pH}$ ácido) e $265 \mathrm{~nm}$ ( $\mathrm{pH}$ neutro), um poderoso antioxidante, é uma cetolactona do ácido 2,3-dienolgulônico de seis carbonos, sendo um potente agente redutor que se oxida facilmente e de modo reversível a ácido L-deidroascórbico. ${ }^{8,9}$ Em solução aquosa, a hidroxila do carbono 3 se ioniza com rapidez $\left(\mathrm{pK}_{1}=4,04\right.$ a $25^{\circ} \mathrm{C}$ mais ácido que o ácido acético) e uma solução de ácido livre tem um $\mathrm{pH}$ de $2,5 .{ }^{6} \mathrm{O}$ segundo grupo hidroxila é muito mais resistente à ionização $\left(\mathrm{pK}_{2}=11,4 \mathrm{a} 25^{\circ} \mathrm{C}\right)$. $\mathrm{O}$ anel 1,4 lactona estável deriva de hexoses, a acidez é justificada primeiramente devido à extensão da conjugação da carbonila presente no carbono 1 , aumentando a característica ácida da hidroxila no carbono $3 .^{8}$

Por ser um potente agente redutor, provavelmente pode interferir nos ensaios laboratoriais que utilizam reações de oxidorredução causando um falso resultado na análise. ${ }^{10} \mathrm{Em} \mathrm{pH}$ neutro ou alcalino, o ácido ascórbico encontra-se predominantemente na sua forma ionizada, o ascorbato. Em plantas, o ascorbato encontra-se em concentrações relativamente elevadas (2 a $25 \mathrm{mM}$ ) e atua na desintoxicação do peróxido de hidrogênio., ${ }^{9,11}$

Diferentes autores ${ }^{10,12}$ relatam que o ácido ascórbico em concentrações acima de 40-50 $\mathrm{mg} \mathrm{dL}^{-1}$ interferem nos resultados das análises de glicose no sangue e na urina e que esta interferência é diretamente proporcional à concentração da vitamina $\mathrm{C}$ e inversamente proporcional à concentração dos analitos, mascarando os resultados.

Conforme metodologia descrita na ref. 13, método 064/IV, ácido ascórbico, ácido eritórbico, ascorbato de sódio e eritorbato de sódio, em amostras puras ou em misturas de aditivos que não apresentem outras substâncias redutoras, podem ser identificados por redução da solução de Fehling.

Esse trabalho teve como objetivo verificar a estabilidade do ácido ascórbico sob aquecimento em meio ácido e alcalino e avaliar a interferência do ácido ascórbico na determinação de açúcares redutores e totais pelo método de Lane e Eynon.

\section{PARTE EXPERIMENTAL}

O experimento foi conduzido no laboratório de Bioquímica do Centro de Ciências Exatas e Tecnológicas da UFRB, BA. Foram testadas soluções de ácido ascórbico, de glicose e de sacarose em diferentes concentrações, em dois ensaios, para avaliar a interfência do ácido ascórbico na determinação dos açúcares redutores e totais, pelo método de Lane e Eynon, em soluções de concentração conhecida.

Foram realizados dois ensaios em delineamento inteiramente casualizado; o primeiro com dois fatores ácido ascórbico e glicose em esquema fatorial $5 \times 5$, cinco concentrações de ácido ascórbico $(0,0 ; 0,5 ; 1 ; 1,5$ e $2 \%)$ e cinco concentrações de glicose $(0,0 ; 0,5 ; 1$; 1,5 e $2 \%$ ), excluindo-se a interação $0,0 \%$ de ácido ascórbico x $0,0 \%$ de glicose, com seis repetições. O segundo ensaio foi realizado com dois fatores em esquema fatorial $7 \times 5$, sete concentrações de ácido ascórbico $(0,0 ; 0,25 ; 0,5 ; 1 ; 1,5 ; 2$ e $2,5 \%)$ e cinco concentrações de sacarose $(0,0 ; 0,5 ; 1 ; 1,5$ e $2 \%)$, excluindo-se a interação $0,0 \%$ de ácido ascórbico x $0,0 \%$ de sacarose, em seis repetições.

\section{Primeiro ensaio - açúcares redutores}

A determinação dos açúcares redutores foi realizada pelo método de Lane e Eynon, que utiliza o licor ou solução de Fehling, conforme descrito na ref. 13: foram transferidos para um erlenmeyer de 250 $\mathrm{mL}$, com auxílio de pipeta, $5 \mathrm{~mL}$ da solução A e $5 \mathrm{~mL}$ da solução B de Fehling, e adicionados $50 \mathrm{~mL}$ de água destilada, aquecendo-se até a ebulição. Em seguida a amostra teste foi transferida para uma bureta de $25 \mathrm{~mL}$ e adicionada gota a gota sobre a solução de Fehling, em ebulição, agitando-se sempre até que a solução passou da cor azul a incolor. No fundo do erlenmeyer ficou um resíduo avermelhado, quando foram adicionadas 2 a 3 gotas de azul de metileno e concluída a titulação com a mudança de coloração.

O licor de Fehling foi padronizado anteriormente com uma solução de glicose a 0,5\% v/v em água, com seis repetições.

Cálculo: $\frac{100 \times \mathrm{A} x \mathrm{a}}{\mathrm{P} \times \mathrm{V}}=$ glicídios redutores, em $\%$ de glicose $(\mathrm{m} / \mathrm{m})$

$\mathrm{A}=\mathrm{mL}$ da solução da amostra gasta na titulação; $\mathrm{a}=$ título do Fehling ( $\mathrm{n}^{\mathrm{o}}$ de gramas de glicose, correspondente a $10 \mathrm{~mL}$ da solução de Fehling); $\mathrm{P}=\mathrm{g}$ da amostra (ou volume inicial da amostra); $\mathrm{V}=$ volume da amostra gasto na titulação.

A fórmula simplificada pode ser expressa como:

Glicídios Redutores em glicose $(\%)=\frac{\mathrm{a} x 100}{\mathrm{~V}}$

As amostras do primeiro ensaio que passaram pela análise de Lane e Eynon foram as diferentes concentrações da solução de glicose pura P.A., as diferentes concentrações das soluções de ácido ascórbico puro P.A. e as diferentes combinações das soluções de glicose e ácido ascórbico para avaliação dessas combinações.

\section{Segundo ensaio - açúcares totais}

A inversão da sacarose foi feita por hidrólise ácida, utilizandose $25 \mathrm{~mL}$ da amostra aquecida a $67-70{ }^{\circ} \mathrm{C}$, que recebeu a adição de $0,5 \mathrm{~mL}$ de $\mathrm{HCl}$ concentrado e permaneceu em banho-maria, durante 15 min, após o que o sistema foi resfriado à temperatura ambiente e neutralizado com solução de hidróxido de sódio a 30\%, o que foi verificado com adição de gotas de fenolftaleína e/ou com o uso de tiras de papel de tornassol. A solução foi transferida para um balão volumétrico de $100 \mathrm{~mL}$ e o volume foi completado com água destilada. Essas amostras contendo açúcar (invertido), ácido ascórbico, ou a mistura de ambos, encontravam-se diluídas 1:4 e a partir daí foi feita a determinação, conforme descrito para o primeiro ensaio.

Todas as amostras deste ensaio passaram pelo processo de hidrólise ácida, tanto as soluções de sacarose pura nas diferentes concentrações como as soluções de ácido ascórbico puro nas seis concentrações estabelecidas, assim como as combinações das soluções de ácido ascórbico e de sacarose, para se avaliar o efeito dessas concentrações através da análise pelo método de Lane e Eynon. As soluções de ácido ascórbico também foram submetidas ao efeito do $\mathrm{HCl}$ sob aquecimento para averiguar sua estabilidade sob estas condições.

Em ambos os ensaios os resultados foram submetidos à análise de variância e análise de regressão utilizando-se o programa SAEG 8.0 ${ }^{\circledR}$ (Sistema de Análise Estatística de Viçosa - MG). ${ }^{14}$

\section{RESULTADOS E DISCUSSÃO}

No primeiro ensaio a análise da variância (ANOVA) mostrou que houve efeito do ácido ascórbico como agente redutor e foi altamente significativo ao nível de $1 \%$ de probabilidade com um CV de $2,82 \%$. 
Na Figura 2A, ficou evidenciado pela análise de regressão que houve um efeito linear do ácido ascórbico como agente redutor, com um $\mathrm{R}^{2}$ de $99,83 \%$. Na Figura 3A pode ser vista a curva padrão do método, obtida para solucões de concentração conhecida de glicose, com os valores de poder redutor esperados na ausência do ácido ascórbico, com um $\mathrm{R}^{2}$ de $99,90 \%$.

Os resultados encontrados no primeiro ensaio evidenciaram a capacidade redutora do ácido ascórbico quando submetido ao método de Lane e Eynon expressando um poder redutor sobre o licor de Fehling correspondente a $74,83 \%$, em média, do poder redutor da glicose. Pela ANOVA houve efeito significativo para todas as concentrações e interações das diferentes concentrações do ácido ascórbico com as soluções de glicose estudadas, ao nível de $1 \%$ de probabilidade.
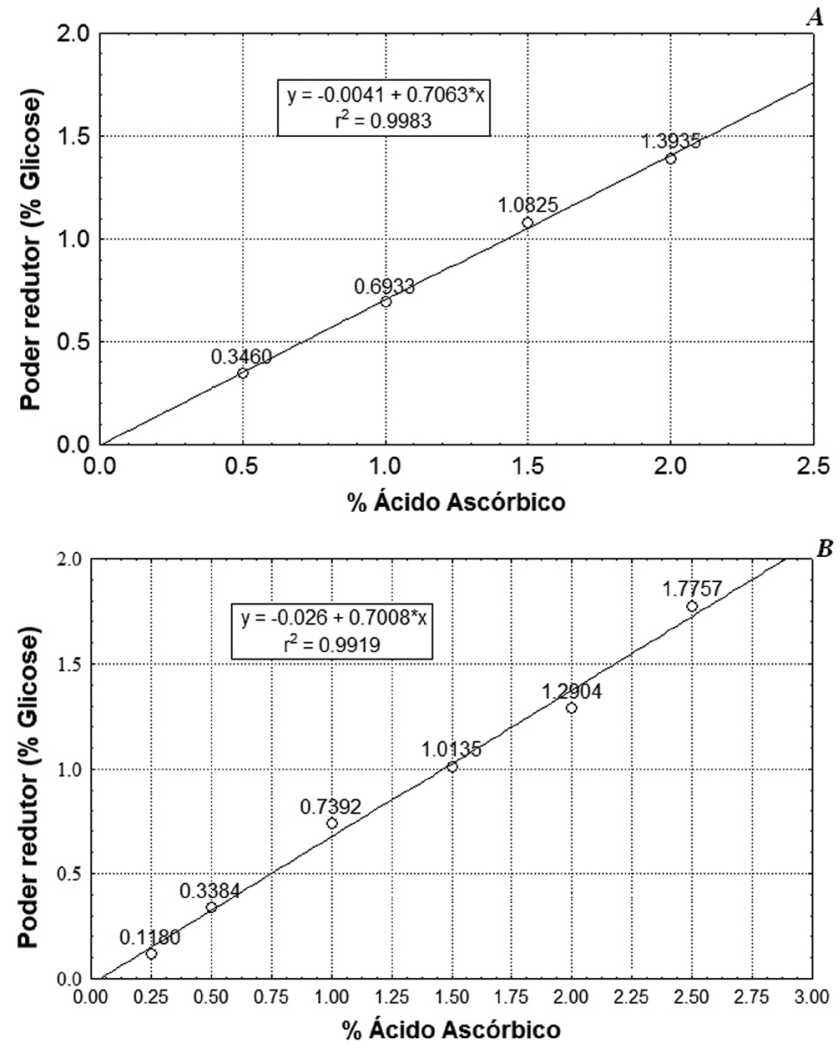

Figura 2. Capacidade redutora do ácido ascórbico sobre o licor de Fehling, expressa em porcentagem de glicose, durante a determinação de (A) açúcares redutores e $(B)$ açúcares totais pelo método de Lane e Eynon $(p \leq 0,01)$

Na Figura 4A, pode-se observar, através da superfície de resposta oriunda da combinação das diferentes concentrações de ácido ascórbico com as diferentes concentrações de glicose, o efeito da atividade redutora do ácido ascórbico sobre o resultado da análise, com o aumento proporcional da redução do licor de Fehling. As análises de regressão expressas pela equação $\hat{Y}=-0,059315+0,748339 A+1,014650 \mathrm{G}$, onde A corresponde ao teor de ácido ascórbico e $\mathrm{G}$ ao teor de glicose, evidenciam que a associação promoveu o aumento da redução do reagente de Fehling em todos os níveis de ácido ascórbico utilizados no ensaio, em uma proporção constante e linear com um $\mathrm{R}^{2}$ de $99,53 \%, p \leq 0,01$. Ficou demonstrado que para cada acréscimo de $1 \%$ do teor de ácido ascórbico na solução houve uma elevação média de $74,83 \%$ no teor de glicose total.

No segundo ensaio de açúcares totais, com hidrólise da sacarose, pode-se observar que o ácido ascórbico manteve seu poder redutor sobre reagente de Fehling, mesmo depois de passar pelo processo de aquecimento em presença de ácido clorídrico e posterior neutralização com solução de hidróxido de sódio a $30 \%(\mathrm{~m} / \mathrm{v})$. Este efeito, pela ANOVA, foi altamente significativo ao nível de $1 \%$ de probabilidade, obtendo-se um CV de apenas 1,372\%.

Na Figura 2B, ficou evidenciado que houve um efeito linear do ácido ascórbico como agente redutor, para as seis concentrações avaliadas, com um $\mathrm{R}^{2}$ de 99,19\%. Na Figura 3B pode ser vista a curva padrão do método, obtida para soluções de concentração conhecida de sacarose invertida, com os valores de poder redutor esperados na ausência do ácido ascórbico, com um $\mathrm{R}^{2}$ de 99,60\% .
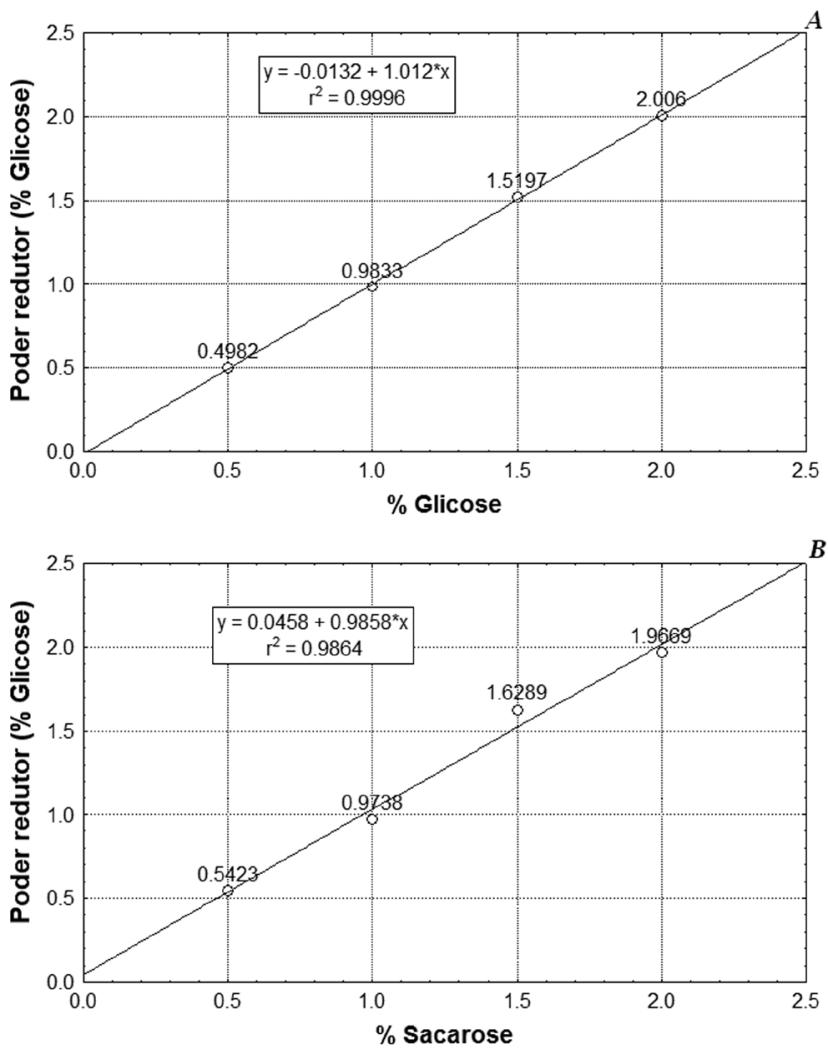

Figura 3. Capacidade redutora das soluções de glicose e de sacarose sobre o licor de Fehling, expressa em porcentagem de glicose, durante a determinação de (A) açúcares redutores e (B) açúcares totais pelo método de Lane e Eynon $(p \leq 0,01)$

A ANOVA evidenciou o efeito significativo do ácido ascórbico para todas as concentrações e interações com as soluções de sacarose estudadas $(\mathrm{p} \leq 0,01)$. Na Figura 4B pode-se observar, através da superfície de resposta, o efeito da combinação das concentrações de ácido ascórbico com as diferentes concentrações de sacarose invertida, no valor do poder redutor expresso em $\%$ de glicose. A asociação promoveu aumento proporcional dos resultados da análise de açúcares totais, seguindo a mesma tendência observada no primeiro ensaio, quando foi utlizada a glicose combinada com as doses de ácido ascórbico. A análise de regressão é expressa pela equação $\mathrm{Y}^{\wedge}=-0,00724272+0,697070 \mathrm{~A}+1,01590 \mathrm{~S}$, onde A corresponde ao teor de ácido ascórbico e $\mathrm{S}$ o teor de sacarose invertida (açucares totais).

A presença do ácido ascórbico junto com as diferentes concentrações de sacarose promoveu o aumento da redução do reagente de Fehling em todas as concentrações de ácido ascórbico utilizadas no ensaio, em uma proporção constante e linear, com um $\mathrm{R}^{2}$ de $99,12 \%$. Ficou evidenciado que para cada acréscimo de $1 \%$ no teor de ácido ascórbico houve uma elevação média de $69,71 \%$ no teor de sacarose invertida total.

Várias fontes ${ }^{6,713}$ relatam que o ácido ascórbico é muito sensível 


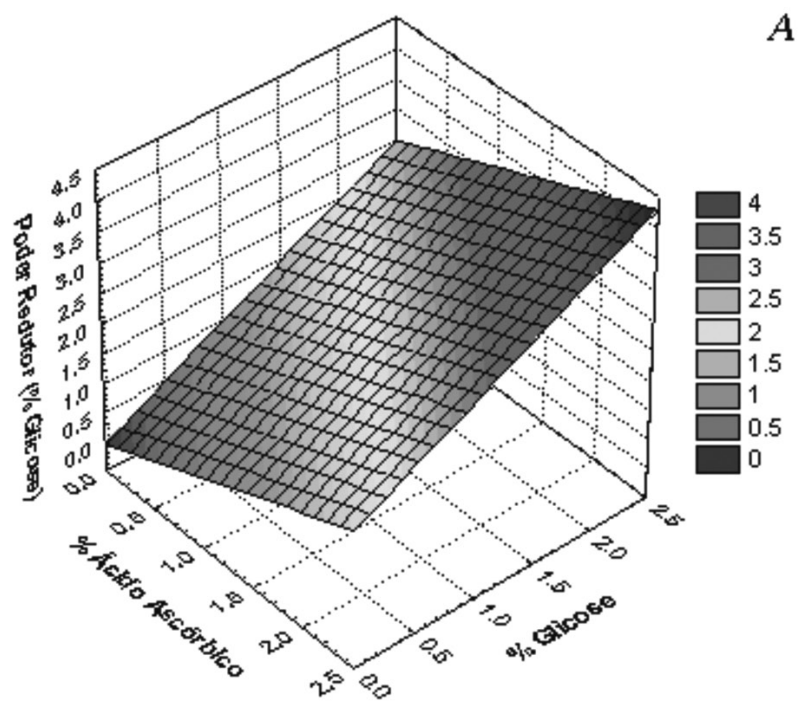

$A$

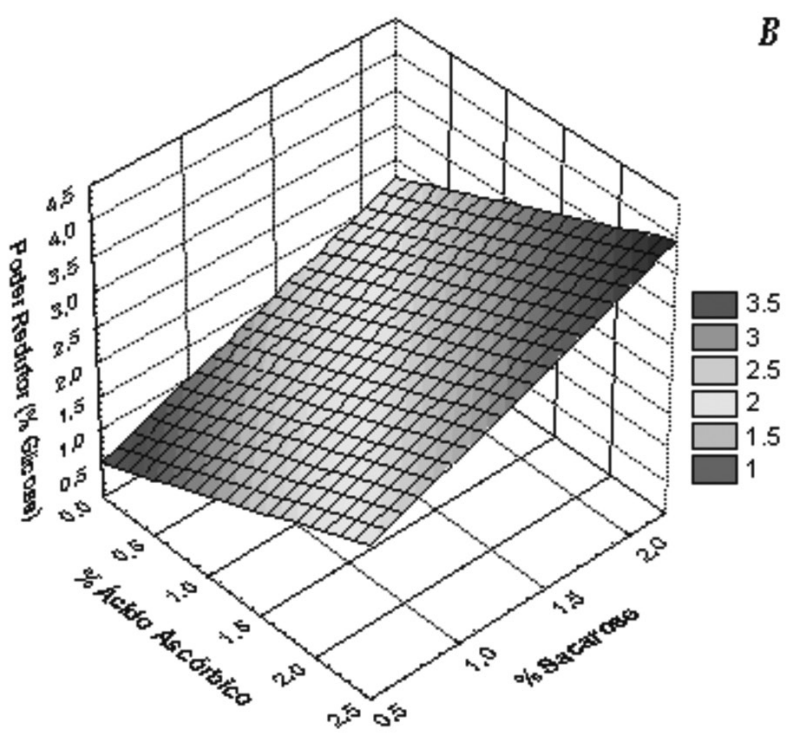

Figura 4. Superfície de resposta do efeito da combinação das cinco diferentes concentrações de ácido ascórbico com diferentes concentrações de (A) glicose e (B) sacarose invertida, nos resultados de açúcares redutores e totais expressos em termos de poder redutor em porcentagem de glicose determinado pelo método de Lane e Eynon e ajustada pela equação $\hat{\mathrm{Y}}=$ $-0,059315+0,748339 A+1,014650 G\left(p \leq 0,01-R^{2}=0,9953\right)$ para glicose e pela equação $\hat{\mathrm{Y}}=-0,00724272+0,697070 A+1,01590 S\left(p \leq 0,01-R^{2}=0,9912\right)$ para a sacarose

às diversas formas de degradação oxidativa e a numerosos fatores, como temperatura, oxigênio, enzimas, luz e catalisadores metálicos (como $\mathrm{Cu}^{+2} \mathrm{e} \mathrm{Fe}^{+3}$ ). Ainda segundo Ribeiro e Seravali, ${ }^{7}$ a velocidade da oxidação aeróbica é dependente do $\mathrm{pH}$, sendo mais rápida e mais intensa em meio alcalino $(\mathrm{pH} \geq 8,0)$. Em $\mathrm{pH}$ muito ácido $(\mathrm{pH} \leq 1,5)$, o íon hidrogênio catalisa a decomposição do ácido ascórbico pela hidrólise do anel da lactona e, com a adicional descarboxilação e desidratação, ocorre a formação do furfural e de ácidos orgânicos. Entretanto, as soluções do ácido ascórbico utilizadas no segundo ensaio foram submetidas à ação de ácido clorídrico, sob aquecimento, e posterior neutralização com $\mathrm{NaOH}$ a $30 \%$; em seguida, durante as análises pelo método de Lane e Eynon, foram submetidas à fervura a $105{ }^{\circ} \mathrm{C}$ em meio alcalino. Foi observado que nessas condições o ácido ascórbico, manteve sua atividade redutora, apresentando relativa estabilidade, comportando-se como ose.
O efeito linear das concentrações de ácido ascórbico nos dois ensaios deixa evidente a interferência deste constituinte nos resultados da análise de açúcares redutores, pelo método de Lane e Eynon. Esse efeito mascara o resultado final da análise e, possivelmente, pode interferir em todos os outros métodos de análise de açúcares redutores e totais que utilizam a redução do cobre e outros metais como princípio da metodologia.

Para a maioria das frutas, vegetais e alimentos em geral, com baixos teores de ácido ascórbico ( 1 a $\left.300 \mathrm{mg} 100 \mathrm{~g}^{-1}\right)$ essa interferência é pouco expressiva. Entretanto, existem alimentos, frutas e vegetais muito ricos em vitamina $\mathrm{C}$, a exemplo da acerola (Malphigia emarginata), com teores de 800 a $3.000 \mathrm{mg}$ de ácido ascórbico por $100 \mathrm{~g}$ de polpa e teores de açucares redutores na faixa de 3,3 e 5,49 g 100

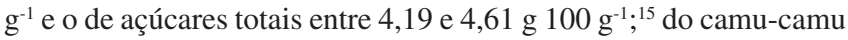
ou caçari (Myrciaria dubia), com teores do mesmo nutriente variando de 2.000 a 5.000 mg $100 \mathrm{~g}^{-1}$ e 3,1 g $100 \mathrm{~g}^{-1}$ de açúcares redutores $;^{16} \mathrm{da}$ cabeluda ou cabeludinha (Eugenia tomentosa ou Plinia glomerata) com $3.000 \mathrm{mg} 100 \mathrm{~g}^{-1},{ }^{17}$ e do goji (Lycium elegantus barbarum) com $2.500 \mathrm{mg} 100 \mathrm{~g}^{-1}$ de ácido ascórbico..$^{18}$ Nesses casos, provalvelmente, os efeitos podem ser altamente relevantes, mascarando os resultados das análises.

Para evitar que resultados de análise de açúcares redutores e totais sejam mascarados pela interferência da ação do ácido ascórbico, no uso do método de Lane e Eynon e outros métodos que tenham como princípio básico a redução de metais como o cobre, sugere-se a seguinte fórmula de cálculo do erro proporcionado pela presença de ácido ascórbico em elevadas concentrações (acima de 500 mg $100 \mathrm{~g}^{-1}$ ) e baixas concentrações de açúcares.

Glicídios redutores, em $\%$ de glicose $(\mathrm{m} / \mathrm{m})=\frac{100 * \mathrm{~A} * \mathrm{a}}{\mathrm{P} * \mathrm{~V}}-(C * 0,75)$

$\mathrm{A}=\mathrm{mL}$ da solução da amostra diluída gasta na titulação; $\mathrm{a}=$ título do Fehling ( $\mathrm{n}^{\circ}$ de gramas de glicose, correspondente a $10 \mathrm{~mL}$ da solução de Fehling); $\mathrm{P}=\mathrm{g}$ da amostra (ou volume inicial da amostra); $\mathrm{V}=$ volume da amostra em $\mathrm{mL}$ gasto na titulação $\left(\mathrm{C}^{*} 0,75\right)=[$ Teor

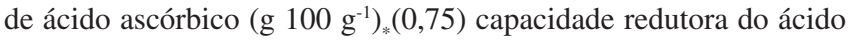
ascórbico em relação à glicose].

No caso dos açúcares totais o fator seria $\left(\mathrm{C}_{*} 0,70\right)$ [teor de ácido

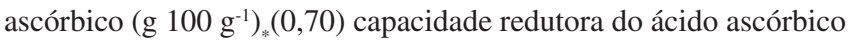
em relação à sacarose invertida].

Para a expressão dos resultados em \% de açúcares não redutores ou em \% de sacarose há necessidade de multiplicar o resultado obtido pelo fator 0,95 .

Glicídios não redutores, em $\%$ de sacarose $\mathrm{m} / \mathrm{m}=\frac{100 * \mathrm{~A} * \mathrm{a}}{\mathrm{P} * \mathrm{~V}} * 0,95-(\mathrm{C} * 0,70)$

\section{CONCLUSÕES}

O ácido ascórbico apresentou estabilidade durante todo o processo de análise, quando submetido ao meio ácido $(\mathrm{HCl})$ sob aquecimento e em meio alcalino a $105^{\circ} \mathrm{C}$. O poder redutor das diferentes doses do ácido ascórbico sobre o licor de Fehling foi equivalente, em média, a 74,83\% do poder redutor da glicose e $69,71 \%$ do poder redutor da sacarose hidrolisada. O ácido ascórbico interfere significativamente nos resultados da análise de açúcares redutores e de açúcares totais pelo método de Lane e Eynon e essa interferência é mais significativa em alimentos com o conteúdo de vitamina $\mathrm{C}$ acima de $500 \mathrm{mg} 100 \mathrm{~g}^{-1}$. Tendo em vista que este estudo foi realizado com soluções puras e como os alimentos e frutos são matrizes complexas, onde existem diferentes interferentes, agentes oxidantes e redutores, recomenda-se estudos mais aprofundados. 


\section{REFERÊNCIAS}

1. http://www-unix.oit.umass.edu/ mcclemen/581Carbohydrates.html, acessada em Abril 2009

2. Silva, R. do N.; Monteiro, V. N.; Alcanfor, J. D. X.; Assis, E. M.; Asquiere, E. R.; Ciênc. Tecnol. Aliment. 2003, 23, 337.

3. Demiate, I. M.; Wosiacki, G.; Czelusniak, C.; Nogueira, A.; Ciências Exatas e da Terra, C. Agrárias e Engenharias 2002, 8, 65.

4. Litwack, G.; Experimental Biochemistry - A Laboratory Manual, John Wiley \& Sons, Inc.: New York, 1960.

5. http://www.scribd.com/doc/6703108/Apostila-Biotecnologia-deAlimentos, acessada em Abril 2009.

6. Fennema, O. R.; Química de los Alimentos, $2^{\text {a }}$ ed., Acribia: Zaragoza, 1993.

7. Ribeiro, E. P.; Seravali, E. A. G.; Química de Alimentos, Edgard Blücher: São Paulo, 2004

8. Nelson, D. L.; Cox, M. M.; Lehninger - Princípios de Bioquímica, $4^{\mathrm{a}}$ ed., Sarvier: São Paulo, 2006.
9. Rosa, J. S.; Godoy, R. L. O.; Oiano Neto, J.; Campos, R. da S.; Matta, V. M.; Freire, C. A.; Silva, A. S.; Souza, R. S.; Ciênc. Tecnol. Aliment. 2007, 27, 787.

10. Martinello, F.; Silva, E. L.; J. Bras. Pat. Med. Lab. 2003, 39, 323.

11. Voet, D.; Voet, J. G.; Bioquímica, $3^{\mathrm{a}}$ ed., Artmed: Porto Alegre, 2006.

12. http://laborlab.com.br/imunologia/URILYSE.doc, acessada em Outubro 2008.

13. Instituto Adolfo Lutz; Métodos físico-químicos para análise de alimentos, $4^{\mathrm{a}}$ ed., IAL: São Paulo, 2004.

14. SAEG - Sistema para Análises Estatísticas, 8.0: Fundação Arthur Bernardes, UFV, Brasil, 2007.

15. Freitas, C. A. S.; Maia, G. A.; Costa, J. M. C.; Figueiredo, R. W. de; Sousa, P. H. M. R.; Bras. Agroc., 2006, 12, 395.

16. Justi, K. C.; Visentainer, J. V.; Souza, N. E. de; Matsushita, M.; ALAN 2000, 50, 405; Silva, C. T. C.; Andrade, J. S.; Acta Hort. 1997, 452, 23.

17. Villela, G. G.; Bacila, M.; Tastaldi, H.; Bioquímica, $4^{\mathrm{a}}$ ed., Guanabara Koogan: Rio de Janeiro, 1978.

18. Qi, Z.; Le, S.; Wu J.; Qu, R.; Yang, Y.; Zhang, L.; Yang, X.; Chinese Herb News 1986, 11, 41. 